\title{
BMJ Open What is the evolution of stroke unit's accessibility in metropolitan France from 2009 to 2014? A trend analysis of over 600000 patients using national hospital databases.
}

\author{
Marion Istvan, ${ }^{1}$ Camille Lecoffre,${ }^{2}$ Sahar Bayat, ${ }^{1}$ Yannick Béjot, ${ }^{3}$ Yann Le Strat, ${ }^{2}$ \\ Christine De Peretti, ${ }^{4}$ Fei Gao, ${ }^{1}$ Valérie Olié, ${ }^{2}$ Olivier Grimaud ${ }^{1}$
}

To cite: Istvan M, Lecoffre C, Bayat $\mathrm{S}$, et al. What is the evolution of stroke unit's accessibility in metropolitan France from 2009 to 2014 ? A trend analysis of over 600 000 patients using national hospital databases.. BMJ Open 2018;8:e023599. doi:10.1136/ bmjopen-2018-023599

- Prepublication history and additional material for this paper are available online. To view these files, please visit the journal online (http://dx.doi org/10.1136/bmjopen-2018023599).

Received 18 April 2018

Revised 10 July 2018

Accepted 17 August 2018

Check for updates

(C) Author(s) (or their employer(s)) 2018. Re-use permitted under CC BY-NC. No commercial re-use. See rights and permissions. Published by BMJ.

${ }^{1}$ Univ Rennes, EHESP, Recherche en pharmaco-épidémiologie et recours aux soins, Rennes, France

${ }^{2}$ Santé publique France - The French Public Health Agency, F94415 Saint-Maurice, France ${ }^{3}$ Service de Neurologie Générale, Vasculaire et Dégénérative, CHU Dijon Bourgogne, Registre Dijonnais des AVC, Dijon, France ${ }^{4}$ Direction de la Recherche, des Etudes, de l'Evaluation et des Statistiques, Paris, France

Correspondence to

Marion Istvan;

istvan.marion@gmail.com

\section{ABSTRACT}

Objectives We aimed to study trends in stroke unit (SU) admission during a period of their deployment in France and to assess whether this led to better and more equitable access to this specialised care.

Design Analysis of records from the national hospital database.

Setting All acute care hospitals in metropolitan France for the period 2009-2014.

Participants Over 600000 patients admitted in acute care with a main diagnosis of stroke.

Main outcome measures Admission to a SU.

Results Between 2009 and 2014, the number of stroke admissions rose from 93728 to 109 456, and the proportion of SU admission from $23 \%$ to $44 \%$. Overall, characteristics associated with higher probability of SU admission were: male gender, younger age, ischaemic stroke type, medium level of comorbidity and larger size of town of residence. Although likelihood of SU admission increased in all patients' categories during the study period, we identified steeper positive temporal trends among older patients, those with more comorbidities and those residing in medium or small towns (all $p$ values $<0.001$ ), suggesting a 'catching up' phenomena. Temporal trends of men and women did not differ however.

Conclusions Admission to SU nearly doubled in France between 2009 and 2014. Faster trends observed for patients with lower admission to SU suggest that equity in access has improved over the period.

\section{INTRODUCTION}

Considerable progresses in the treatment of patients who had stroke have been achieved in the last decades, admission to organised inpatient care for stroke, also named stroke units (SU), being a clinically important one. Available evidence from systematic review suggests that SU admission compared with general wards reduces the risk of death, institutionalisation and dependency by about $20 \%$. ${ }^{1}$ Deployment of SU has varied from country to
Strengths and limitations of this study

- The study relies on a national exhaustive database of hospital admissions for stroke in France.

- We were able to analyse trends of access to stroke unit over a 6-year period while the National Stroke Action Plan was being implemented.

- Specificity of clinical information (e.g., for identifying comorbidities) in hospital records is not as high as in purposely designed epidemiological studies.

country. ${ }^{2}$ In France, national guidelines were issued in $2002^{3}$ and updated in $2009^{4}$ which both recommended that every patient who had stroke should be assessed for admission to a SU. Despite these, SU remained in short supply in France, so much so that only $25.9 \%$ of patients who had stroke were admitted in $2009 .{ }^{5}$ It is likely that this shortage resulted in the selection of patients with better prospect for recovery, and in denial for patients who, despite being older, having more comorbidities, and living further from SU, could still have benefited from SU admission. The supply of SU evolved dramatically however with the impetus of the government's '20102014 National Stroke Action Plan, ${ }^{6} 7$ leading to a rise from $87 \mathrm{SU}$ in $2010^{6}$ to $116 \mathrm{SU}$ in $2012^{8}$. This translated into a near doubling of the proportion of SU admissions, recently estimated at $43 \%$ for the year $2014 .^{9}$

We hypothesised that this rapid deployment of SU supply led to changes in the profile of patients admitted. Our study objectives were first to describe the trend of SU admission over the period, second to identify stroke case's characteristics associated with SU admission and third to determine whether the influence of these characteristics has evolved over the period. 


\section{MATERIALS AND METHODS}

\section{Data}

With authorisation from the 'Commission Nationale Informatique Liberté' (national authority for data protection), we obtained the French Hospital Discharge Database ${ }^{10}$ (thereafter hospital databases) from the 'Agence Technique de l'Information Hospitalière' a national agency responsible for compiling all admissions in French hospitals. Although the hospital databases are mainly used for financing purposes, it contains a wealth of demographic, clinical and therapeutic information and has proved a valuable tool for analysing trends in stroke hospitalisations and care. ${ }^{112}$ We selected hospitalisations with a discharge's date between January 2009 and December 2014 among residents of metropolitan France all ages considered. Metropolitan France is the mainland part of France and French islands in the Atlantic Ocean, English Channel and Mediterranean Sea, located in Europe. We identified stroke admissions as records with the following main diagnosis using the 10th revision of International Classification of Disease: I61 (intracerebral haemorrhage), I63 (cerebral ischaemic necrosis) and I64 (undetermined stroke). Admissions with main diagnosis codes I60 and G46 were excluded because they have been shown to be less predictive of being principally motivated by an incident stroke. ${ }^{11}$ We also excluded diagnosis code I62 (non-traumatic subdural haemorrhage) because these patients are more relevant to admission to neurosurgical ward than to SU. In order to avoid double counting, we used record linkage to compile an initial short stay $(<2$ days) with a contiguous stay in another ward or hospital for the same patient, since both stays are likely to inform about the care of the same spell of disease. Because we were interested in all stroke admissions, our database includes incident as well as recurrent cases.

\section{Definitions and variables}

The hospital database provides information on medical unit, age, gender and town of residence. We identified SU admission using medical unit codes 17 (SU without intensive care) and 18 (SU with intensive care).

Since hospitals with SU are set in urban areas, we used size of town of residence as an indirect indicator of geographical closeness to SU. In the descriptive analysis, we defined three groups as follows: small ( $<20000$ inhabitants), medium (20 000-99 999) or large ( $\geq 100000)$ based on 2011 population census. ${ }^{13}$ Records also provide detailed information on associated diagnosis that we used to derive a Charlson Comorbidity Index (CCI). This was done with a validated algorithm which identified the presence a set of 12 diseases giving a weighted score ranging from 0 to $24 .{ }^{14-16}$ The list of diseases includes: congestive heart failure (two points), dementia (two points), pulmonary disease (one point), connective tissue disorder (one point), mild liver disease (two points), diabetes with complications (one point), moderate or severe renal disease (one point), tumour (including leukaemia and lymphoma) (two points), metastatic solid tumour (six points), moderate or severe liver disease (four points), HIV-AIDS (four points) and paraplegia or hemiplegia (two points). Since the latter may reflect the severity of the index stroke, as well as correspond to a pre-existing comorbid condition, it is worth noting that in the context of this study the score reflects both comorbidity and stroke severity.

\section{Statistical analysis}

In the descriptive analysis, continuous variables were presented as mean and standard deviation, categorical variables as number and percentage. Temporal trends of demographic, casemix and residential characteristics of patients who had stroke were assessed using linear regression for continuous variables and multinomial logistic regression for categorical variables. We mapped the proportion of SU admission at the aggregate level of the 96 French metropolitan departments (administrative districts) in the years 2009 and 2014. For this purpose, the crude proportion of SU admissions in each department was categorised in four levels: $0 \%-19.9 \%, 20 \%-39.9 \%$, $40 \%-59.9 \%$ and $60 \%-79.9 \%$.

We used logistic regression to explore the influence of patients, stroke and residential characteristics on the probability of SU admission. Because the relationship between independent continuous variables and outcome were not linear, we used fractional polynomials ${ }^{17}$ in order to model the association of SU admission with age, CCI and size of town of residence. In order to assess changes in SU access over the period, we tested whether year of admission exerted significant statistical interaction on the relationship between $\mathrm{SU}$ admission and the following variables: age, sex, CCI and town size. For computational reasons, all analyses at this stage were performed on a $20 \%$ random sample of records $(n=120800)$.

Significance was set at $\mathrm{p}$ value under 0.05 . Data were analysed using STATA V.13 (StataCorp LP). The maps were drawn with Arcgis. According to French laws and regulations, the examination of the protocol by the Ethics Committee was not required.

\section{Patient and public involvement}

There were no patients or public involvement for this study.

\section{RESULTS}

Table 1 shows that the number of hospitalisations for stroke increased from 93728 in 2009 to 109456 in 2014 $(+17 \%)$. Overall, mean age of patients remained stable and the proportion of men increased marginally. Level of comorbidity displayed a positive trend, since $14.5 \%$ of patients had a CCI above 2 in 2014 compared with only $11.4 \%$ in 2009 . There was also a clear trend of decreasing stroke cases being coded as 'undetermined' (from $12.5 \%$ to 5\%), suggesting higher level of diagnosis ascertainment by brain imaging. Stroke hospitalisations with a $\mathrm{SU}$ admission still represented a minority 
Table 1 Characteristics of hospital stays for stroke in metropolitan France from 2009 to 2014 according to admission to stroke unit

$\begin{array}{lllllll}2009 & 2010 & 2011 & 2012 & 2013 & 2014 & \text { P values }\end{array}$

\begin{tabular}{|c|c|c|c|c|c|c|c|}
\hline \multicolumn{8}{|l|}{$\begin{array}{l}\text { Total stroke } \\
\text { admissions }\end{array}$} \\
\hline Number of stays & 93728 & 97203 & 96264 & 101735 & 105614 & 109456 & \\
\hline $\begin{array}{l}\text { Mean age† }(\mathrm{SD}) \\
\text { years }\end{array}$ & $73.8(14.7)$ & 73.9 (14.9) & $74.1(14.8)$ & 73.9 (15.0) & $73.8(15.1)$ & 73.9 (15.0) & 0.385 \\
\hline Men, \% & 49.7 & 49.7 & 49.6 & 50.0 & 50.2 & 50.9 & $<0.001$ \\
\hline \multicolumn{8}{|l|}{$\begin{array}{l}\text { Charlson } \\
\text { Comorbidity Index } \\
\text { (CCl), \% }\end{array}$} \\
\hline 0 points & 53.9 & 50.6 & 48.3 & 47.3 & 45.3 & 44.1 & $<0.001$ \\
\hline $1-2$ points & 34.7 & 37.2 & 38.7 & 39.2 & 40.6 & 41.4 & \\
\hline 3-4 points & 9.0 & 9.7 & 10.3 & 10.6 & 11.1 & 11.3 & \\
\hline$\geq 5$ points & 2.4 & 2.5 & 2.7 & 2.9 & 3.0 & 3.2 & \\
\hline \multicolumn{8}{|l|}{$\begin{array}{l}\text { Stroke subtypes, } \\
\%\end{array}$} \\
\hline $\begin{array}{l}\text { Cerebral } \\
\text { ischaemic } \\
\text { necrosis }\end{array}$ & 69.8 & 71.6 & 72.9 & 73.5 & 75.3 & 76.8 & $<0.001$ \\
\hline $\begin{array}{l}\text { Intracerebral } \\
\text { haemorrhage }\end{array}$ & 17.8 & 17.8 & 18.0 & 18.7 & 18.3 & 18.2 & \\
\hline $\begin{array}{l}\text { Undetermined } \\
\text { stroke }\end{array}$ & 12.5 & 10.7 & 9.1 & 7.9 & 6.4 & 5.0 & \\
\hline
\end{tabular}

With stroke unit

admission

\begin{tabular}{|c|c|c|c|c|c|c|c|}
\hline $\begin{array}{l}\text { Number of stays, } \\
N(\%)\end{array}$ & 21868 (23.3) & $28143(29.0)$ & 32586 (33.9) & 38394 (37.6) & $43080(40.8)$ & $48210(44.0)$ & \\
\hline $\begin{array}{l}\text { Mean age† }(\mathrm{SD}) \text {, } \\
\text { years }\end{array}$ & $68.1(15.0)$ & $68.7(15.0)$ & 69.5 (14.9) & $69.9(14.9)$ & $70.2(14.8)$ & $70.6(14.7)$ & $<0.001$ \\
\hline Men, (\%) & 56.2 & 56.7 & 55.9 & 55.6 & 55.5 & 55.8 & \\
\hline $\mathrm{CCl}, \%$ & & & & & & & $<0.001$ \\
\hline 0 points & 49.4 & 45.3 & 42.9 & 40.8 & 38.4 & 38.4 & \\
\hline $1-2$ points & 38.7 & 42.1 & 43.6 & 45.4 & 46.7 & 46.7 & \\
\hline $3-4$ points & 9.9 & 10.4 & 11.2 & 11.4 & 12.1 & 12.1 & \\
\hline$\geq 5$ points & 2.0 & 2.2 & 2.3 & 2.5 & 2.8 & 2.8 & \\
\hline \multicolumn{8}{|l|}{$\begin{array}{l}\text { Stroke subtypes, } \\
\%\end{array}$} \\
\hline $\begin{array}{l}\text { Cerebral } \\
\text { ischaemic } \\
\text { necrosis }\end{array}$ & 84.1 & 84.7 & 84.6 & 84.6 & 85.7 & 86.4 & $<0.001$ \\
\hline $\begin{array}{l}\text { Intracerebral } \\
\text { haemorrhage }\end{array}$ & 14.0 & 13.7 & 13.6 & 13.9 & 13.3 & 12.7 & \\
\hline $\begin{array}{l}\text { Undetermined } \\
\text { stroke }\end{array}$ & 1.8 & 1.6 & 1.8 & 1.5 & 1.0 & 0.9 & \\
\hline \multicolumn{8}{|l|}{$\begin{array}{l}\text { Without stroke unit } \\
\text { admission }\end{array}$} \\
\hline Number of stays & 71860 & 69060 & 63678 & 63641 & 62534 & 61246 & \\
\hline $\begin{array}{l}\text { Mean aget }(\mathrm{SD}) \text {, } \\
\text { years }\end{array}$ & $75.6(14.2)$ & $76.0(14.2$ & 76.4 (14.3) & $76.3(14.6)$ & $76.3(14.8)$ & $76.6(14.7)$ & $<0.001$ \\
\hline Men, (\%) & 47.8 & 46.9 & 46.5 & 46.5 & 46.6 & 47.0 & 0.002 \\
\hline
\end{tabular}




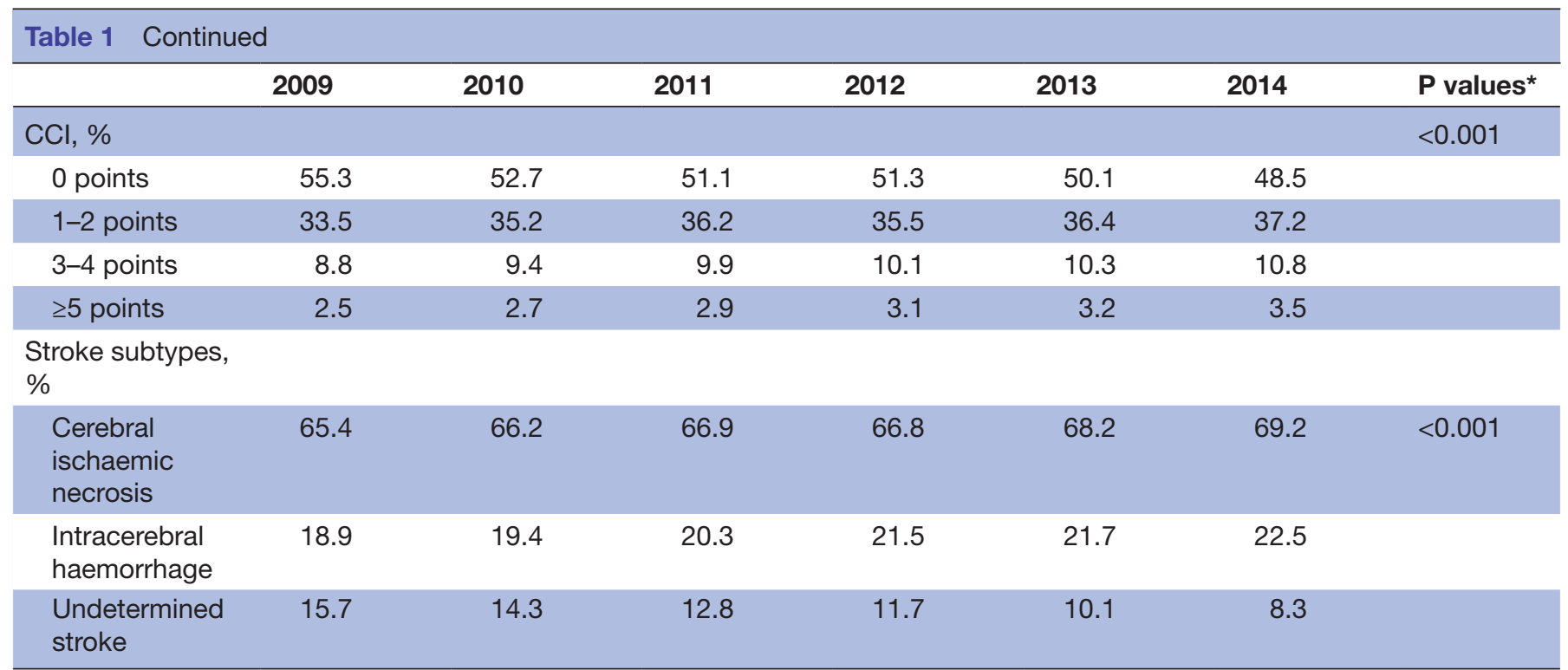

*Linear regression for continuous variables, multinomial logistic regression for categorical variables. †Age: less than $0.5 \%$ of missing values.

of all hospital stays in 2014 (48 210/109 456, 44\%), but their number more than doubled during the period. Compared with other patients, those admitted in SU were younger, more often of the male sex, had more comorbidities and were less often classified as undetermined stroke. The maps in figure 1 illustrate the spread of $\mathrm{SU}$ admissions during the period. In only 1 of the 96 metropolitan French departments was the proportion of SU admissions over $40 \%$ in 2009, compared with 52 departments in 2014. Figure 2 shows that, although the positive trend in SU admissions applied to the three town size categories, in absolute terms the increase

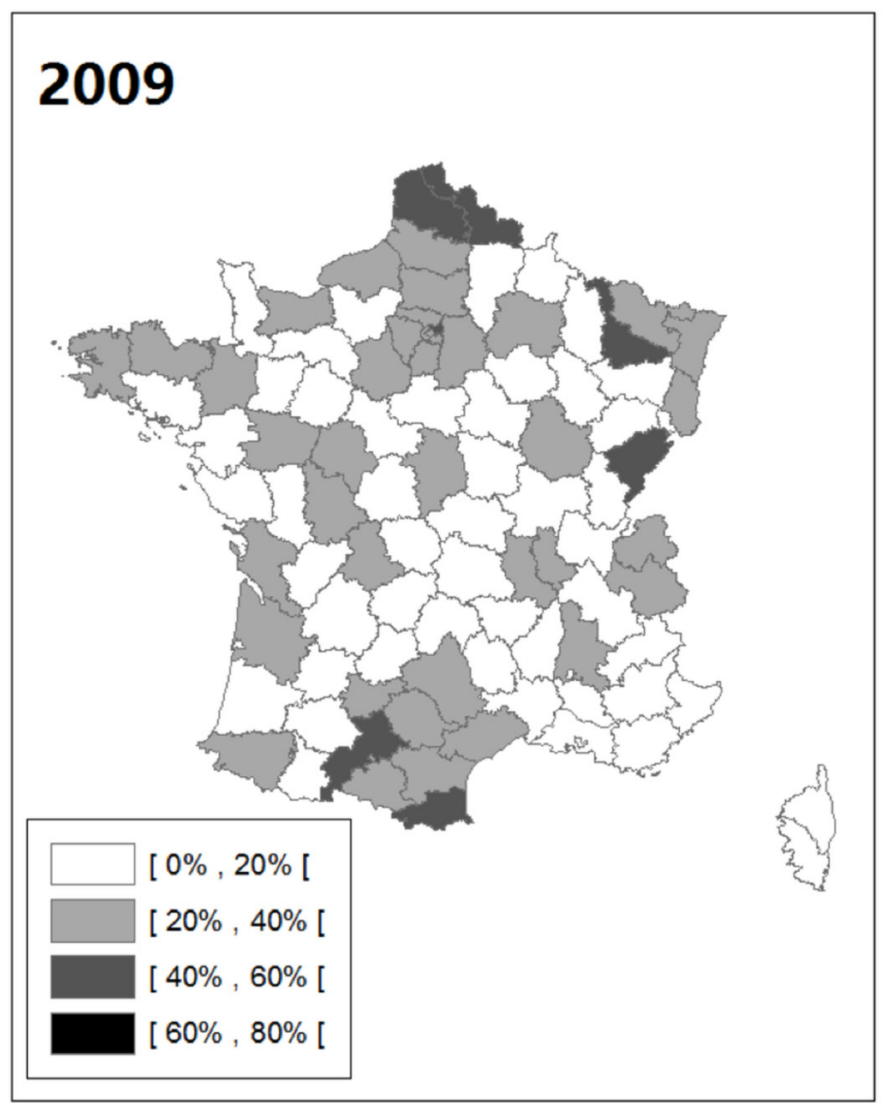

\section{4}

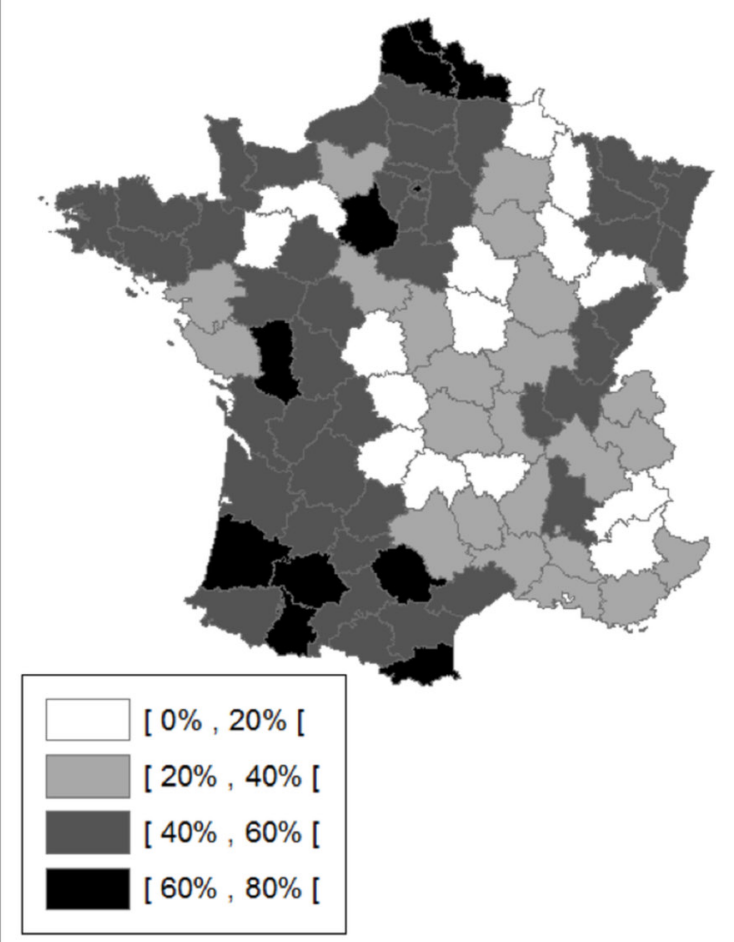

Figure 1 Proportion of admission in stroke unit out of all stroke hospitalisations at the level of French departments ( $\mathrm{n}=96)$ in years 2009 and 2014. 


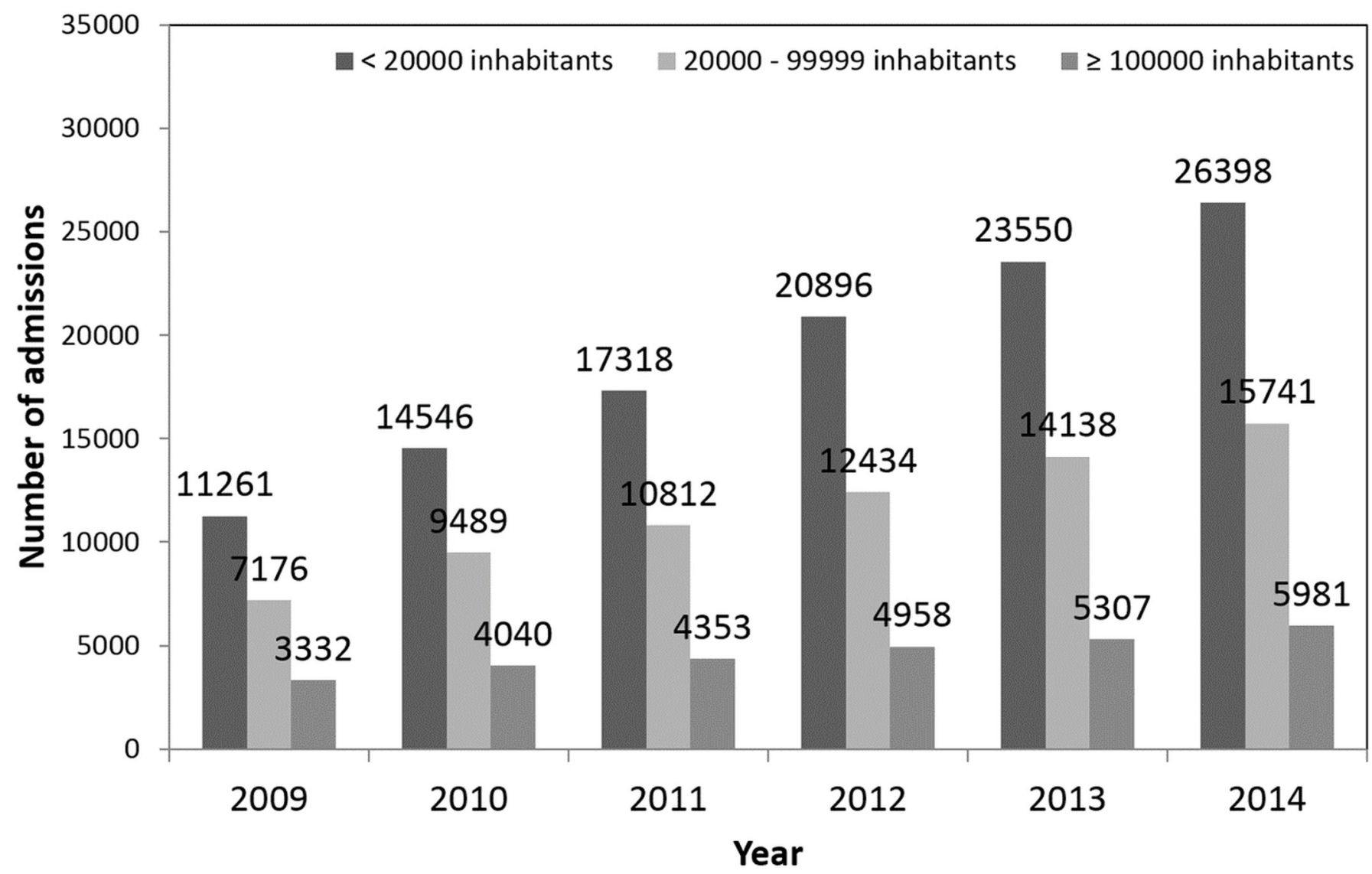

Figure 2 Number of admissions in stroke unit according to size of town of residence from 2009 to 2014. Missing values were excluded in this figure $(0.2 \%-0.5 \%$ of missing values).

concerned mostly patients residing in medium or small towns.

Both patients and stroke characteristics were strongly associated with the probability of SU admission in the multivariable analysis. Table 2 shows multivariable adjusted OR (aOR) from a model fitted on the entire database. Fractional polynomials were used to enter age, $\mathrm{CCI}$ and town size in the model. For these variables, aORs therefore indicate the point estimates of the associations at specified values (e.g., at age 45 years as opposed to the interval 45-54). All associations displayed in table 2 attain high level of statistical significance. There was a strong decreasing trend of SU admission with increasing age, since the aOR of patients aged 85 versus 45 was only 0.26 (95\% CI 0.25 to 0.26$)$. On average over the period, and all other parameters being equals, men had about $10 \%$ more chance of being admitted to a SU compared with women $(\mathrm{aOR}=1.09$ 95\% CI 1.08 to 1.10). Likelihood of $\mathrm{SU}$ admission rise up to a medium level of comorbidity $(\mathrm{CCI}=3)$ and decreased thereafter. Compared with the ischaemic type, haemorrhagic strokes were about half as likely to be admitted to a SU. On average during the period, there was a strong positive trend with increasing town size. Patients residing in large towns $(>100000$ inhabitants) were about twice likely to be admitted in SU compared with those from small towns (2000).
As expected, the ORs for year of admission reflected a strong positive trend over the study period (table 2). However, we found marked and significant variations in the steepness of this trend across patients' subgroups. This is illustrated in figure 3, which shows the temporal trends of SU admission for different modalities of patient or stroke subgroups. The lines show relative risk of SU admission using year 2009 as reference. Clear differences appear across age groups showing that the older the patients, the steeper the positive trend of SU admission. These differences are statistically significant ( $p$ for interaction $<0.001$ ). This suggests a 'catching up phenomena' in favour of older patients, which is also identifiable for patients residing in medium and small towns compared with large towns $(p<0.001)$, and to a lesser extent for those with higher level of comorbidity $(\mathrm{p}=0.002)$. Trends of men and women were similar however $(\mathrm{p}=0.55)$. Ischaemic and haemorrhagic stroke types followed similar trends up to year 2012, after which admission to SU for haemorrhagic cases climbed at a slightly slower rate (not shown).

\section{DISCUSSION}

In this study, we found as expected that $\mathrm{SU}$ admission overall was more likely for younger patients, affected by ischaemic stroke, with low or medium level of comorbidity and living in large towns where SU are settled. We found 


$\left.\begin{array}{lll}\hline \multicolumn{2}{l}{\begin{array}{l}\text { Table } 2 \text { Factors associated with the probability of } \\ \text { admission to a stroke unit }\end{array}} & \text { P values } \\ \hline \multicolumn{3}{c}{\text { aOR }^{*}(95 \% \text { Cl) }} \\ \text { Age† (years) } & \text { Reference } \\ 45 & 0.91(0.90 \text { to } 0.92) \\ 55 & 0.75(0.75 \text { to } 0.76) \\ 65 & 0.46(0.45 \text { to } 0.47) \\ 75 & 0.26(0.25 \text { to } 0.26) \\ 85 & \end{array}\right]<0.001$

$\begin{array}{lll}\text { Gender } & & \\ \text { Women } & \text { Reference } & <0.001 \\ \text { Men } & 1.09(1.08 \text { to } 1.10) & ل\end{array}$

Charlson Comorbidity Index†

$\left.\begin{array}{ll}0 & \text { Reference } \\ 1 & 1.50(1.49 \text { to } 1.51) \\ 3 & 1.90(1.88 \text { to } 1.93) \\ 5 & 1.44(1.41 \text { to } 1.47) \\ 7 & 0.96(0.92 \text { to } 0.99)\end{array}\right\}<0.001$

$\left.\begin{array}{ll}\text { Stroke subtypes } & \\ \text { Ischaemic } & \text { Reference } \\ \text { Haemorrhagic } & 0.47(0.46 \text { to } 0.48) \\ \text { Undetermined } & 0.10(0.09 \text { to } 0.10)\end{array}\right]<0.001$

Sizeł of town of residence $†$

$\left.\begin{array}{ll}2000 & \text { Reference } \\ 12000 & 1.30(1.27 \text { to } 1.34) \\ 51000 & 1.80(1.75 \text { to } 1.84) \\ 103000 & 1.93(1.88 \text { to } 1.99) \\ 203000 & 1.96(1.91 \text { to } 2.02) \\ 447000 & 2.51(2.43 \text { to } 2.59)\end{array}\right]<0.001$

Year of admission

$\left.\begin{array}{ll}2009 & \text { Reference } \\ 2010 & 1.26(1.25 \text { to } 1.26) \\ 2011 & 1.56(1.55 \text { to } 1.57) \\ 2012 & 1.92(1.90 \text { to } 1.94) \\ 2013 & 2.09(2.40 \text { to } 2.44) \\ 2014 & 2.98(2.92 \text { to } 3.03)\end{array}\right]<0.001$

Hospital stays with a diagnosis of stroke in metropolitan France, between 2009 and 2014.

*aOR, adjusted OR.

†Variables entered in the model with fractional polynomials, because of their non-linear relationship with the outcome variable. ORs indicate level of association at each specific value presented (as opposed to intervals between values).

$\ddagger$ As per 2011 population census, rounded to the nearest 1000 .

a strong positive trend in SU admission, which doubled in proportion despite a rise of the number of patients. However, proportion of $\mathrm{SU}$ admission remains lower than in other European countries: $56.9 \%$ in Germany in $2012,{ }^{18} 87.5 \%$ in Sweden in $2010 .^{19}$ An important finding is that, if this positive trend applied to all groups explored, it did so differentially, so that faster trends of SU admission were identified during the 6 year for older patients, those with more comorbidities and living in medium of small towns. In other words, with respect to these characteristics, differential trends have resulted in a reduction of inequalities in access to $\mathrm{SU}$ at the end of the period. However, this did not apply to women whose positive trend followed that of men, and remained less likely to be admitted to SU.

Deployment of specialised health services such as SU requires planning, resources, organisational changes and ultimately time. It is therefore no surprise that territorial differences occur in this process. We showed that territorial access to SU improved significantly between 2009 and 2014, with net progresses in the departments located in the North, North-West, South-West and East of France. We showed that, in absolute terms, 'new' patients accruing to $\mathrm{SU}$ over the period mainly resided in small or medium towns, which are likely to represent more rural areas and being more remote to a hospital. In Ontario, patients who had stroke living in rural areas were less likely to being admitted to SU and had lower use of stroke care interventions. ${ }^{20}$ Given that more than $50 \%$ of patients in our study resided in towns with less than 50 000 inhabitants, there was clear room in 2014 for more progress in providing effective stroke care to this population. It is also worth noticing that our result may mainly reflect the spread of SUs over the territory, whereas in order to demonstrate real geographical improvement in access, one would need to show a positive trend of admission adjusted to the distance to the nearest SU. Databases with detailed patient's and SU's addresses would allow to explore this issue.

Although younger patients were overall much more likely to be admitted to $\mathrm{SU}$, we showed a clear gradient of faster trends in favour of older patients over the study period. This is likely to reflect improvement in geographical access to SU since the populations of medium and small towns are older than that of urban areas in France. It also suggests that in the context of increasing, but nevertheless short, supply, neurologists have been more inclined to consider admission of older patients in SU. The accumulation of evidence showing that specialised care such as thrombolysis and thrombectomy are beneficial to younger and older patients ${ }^{21-24}$ might also have contributed to this trend. In a 2010 review of 90 papers, Appelros et al concluded that there were little evidence of gender differences in stroke care. ${ }^{25}$ Our findings suggest that women in France were about $10 \%$ less likely to be admitted to SU than men, with no catching up between beginning and end of the study period. Given our highly powered study, this difference is statistically significant. What matters more are the robustness and the clinical significance of this result. Women develop stroke at an older age, when they may present with more comorbidities or frailty. Therefore, it is possible that the association we found is still influenced by residual confounding (say 

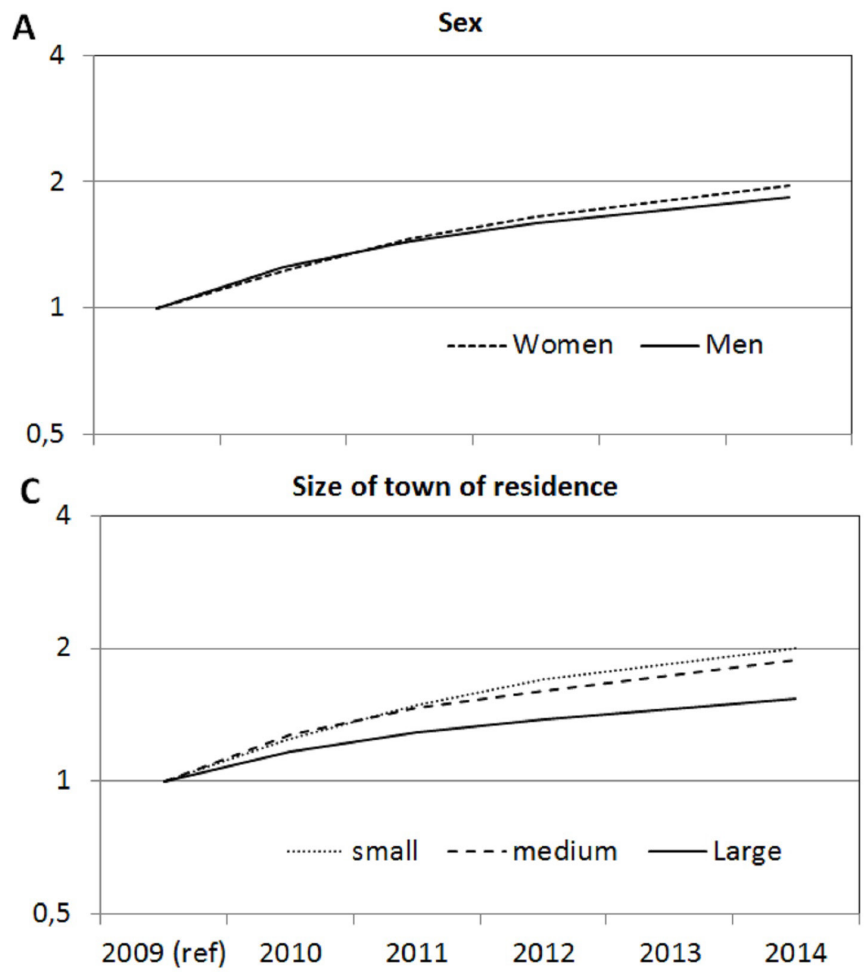
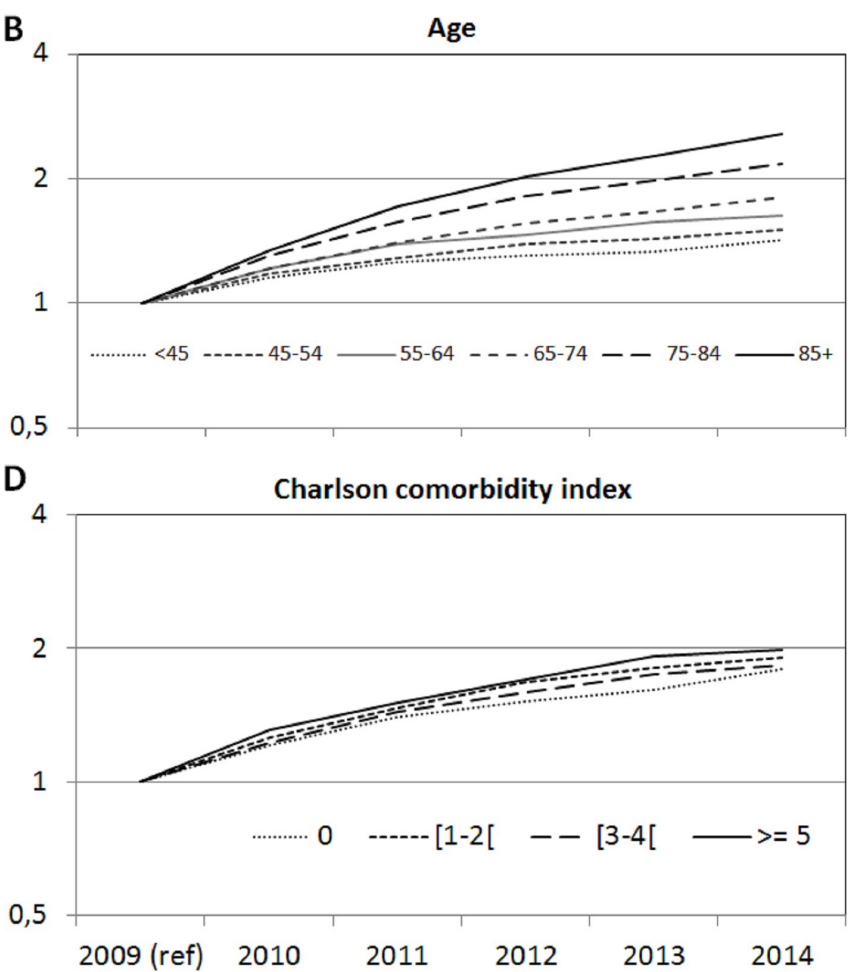

Figure 3 Trends in stroke unit admission (reference level: year 2009=1) according to sex, age, size of town of residence and comorbidity.

regarding comorbidity) or by unmeasured level of severity. Indeed, some studies suggest that severity is higher and functional status lower among women at stroke onset. ${ }^{26-28}$ Differences across gender in the aetiology of stroke have also been identified, with higher prevalence of hypertension and more frequent cardioembolic stroke linked to pre-existing atrial fibrillation among women. ${ }^{26} 27$ Overall, we feel that the question of equal access to effective stroke care across gender in France deserves further investigation, ideally based on rich clinical databases.

As reported by Sheedy et $a l^{29}$ we found that, compared with ischaemic events, patients with haemorrhagic stroke were less likely to be admitted in SU. One possible explanation for this is that, given the higher severity of haemorrhagic strokes, these patients are more often admitted in intensive care unit.

Increasing trends of absolute number of stroke hospitalisations have already been identified in France. ${ }^{5} 3031$ Here, we found an excess of over 15000 cases $(+17 \%)$ in 2014 compared with 2009. An important driver of absolute stroke number in France and comparable countries is the ageing of the population. ${ }^{32}$ There is also evidence that incidence is rising in younger men and women. ${ }^{33}$ Part of the trend in absolute number of cases may also be due to better identification of brain infarction ${ }^{34}$ and qualification as stroke of events which would have previously been labelled as transient ischaemic attacks, especially among the 65 years and older. ${ }^{35}$ This is supported by previous analyses of the French hospital database ${ }^{530}$ and by the decreasing proportion of cases labelled as "undetermined type' in our results. Whether it is from ageing, technological progresses or both, the stark reality is that France and most countries worldwide are likely to experience significant rises in absolute number of patients who had stroke to care for.

A strength of this study is to rely on a national, exhaustive hospital records database which has proved to be a reliable information source for identifying stroke cases. Validation studies, based on main diagnosis at ward level (as opposed to hospital stay, as we have done), have found overall sensitivity for stroke diagnosis as high as $77.1 \%,{ }^{36}$ and positive predictive value of $89 \%, 96 \%$, and $87 \%$, respectively, for diagnostic codes I61, I63 and I64 $4^{11}$ (see table 1 in online supplementary material 1). ${ }^{113637}$ Absolute level of comorbidities may not be accurately estimated in our study first because we had to rely on associated diagnosis coded during the stroke hospital stay as opposed to during the preceding year; second, because we used a validated but restricted list of 12 conditions; and third because we kept the condition hemiplegia in the calculation of the score, thus attributing a stroke severity dimension to the score. Since these methodological features apply to the whole study population, they should not affect year-to-year comparison however. It is also possible that coding of comorbidities might have differed between hospital with and without SU, as well as evolved during the study period. As mentioned above, we used town size as a proxy for the distance between patients' residence and SU. One would also expect that as an indicator, town size amalgamates a number of 
socioeconomic and cultural determinants of health and healthcare-seeking behaviour. Since low socioeconomic status is associated to both stroke incidence and outcome, more epidemiological and qualitative research should be conducted in order to understand how much these associations reflect differing access to preventive, curative or rehabilitative healthcare.

In conclusion, in the context of SU deployment following the national Stroke care plan, the proportion of SU admission more than doubled in France between 2009 and 2014. Older patients who had stroke, those with more comorbidities and those living in smaller towns who are overall less likely to be admitted to SU, followed nevertheless a comparatively faster positive trends, suggesting a move towards more equitable access. More progress needs to be achieved in these lines in order to ensure access to all patients who could benefit from this effective care.

Contributors MI: data analysis and interpretation, drafting the article, critical revision and final approval of the version. CL and CDP: critical revision and final approval of the version. SB: design of the study, data interpretation, critical revision and final approval of the version. YB, YLS and V0: data interpretation, critical revision and final approval of the version. FG: data collection, critical revision and final approval of the version. OG: conception and design of the study, data analysis and interpretation, drafting the article, critical revision and final approval of the version.

Funding This research received no specific grant from any funding agency in the public, commercial or not-for-profit sectors.

Competing interests None declared.

Patient consent Not required.

Provenance and peer review Not commissioned; externally peer reviewed.

Data sharing statement At the time of performing the study, access to the French Hospital Records Database was subject to authorisation from the "Commission Nationale Informatique et Liberté". Regulations are currently evolving for providing varying level of access to researchers and analysts on the ground of ethical and scientific validity criteria.

Open access This is an open access article distributed in accordance with the Creative Commons Attribution Non Commercial (CC BY-NC 4.0) license, which permits others to distribute, remix, adapt, build upon this work non-commercially, and license their derivative works on different terms, provided the original work is properly cited, appropriate credit is given, any changes made indicated, and the use is non-commercial. See: http://creativecommons.org/licenses/by-nc/4.0/.

\section{REFERENCES}

1. Stroke Unit Trialists' Collaboration. Organised inpatient (stroke unit) care for stroke. Cochrane Database Syst Rev 2001;3:CD000197.

2. Moon L, Moïse P, Jacobzone S, et al, 2003. Stroke Care in OECD Countries: a comparison of treatment, costs and outcomes in 17 countries http://www.oecd.org/els/health-systems/2957752.pdf? wb48617274=ADF7DAE6 (accessed 28 Mar 2018).

3. Haute Autorité de Santé (HAS), 2002. Recommandations pour la pratique clinique - Prise en charge initiale des patients adultes atteints d'accident vasculaire cérébral - Aspects médicaux Recommandations http://www.has-sante.fr/portail/upload/docs/ application/pdf/recommandations_2006_10_27_20_02_3_927.pdf (accessed 28 Mar 2018).

4. Haute Autorité de Santé (HAS), 2009. Accident vasculaire cérébral: prise en charge précoce (alerte, phase préhospitalière, phase hospitalière initiale, indications de la thrombolyse) http://www.hassante.fr/portail/upload/docs/application/pdf/2009-07/avc prise en charge_precoce_-_recommandations.pdf (accessed 28 Mar 2018).

5. de Peretti C, Nicolau J, Tuppin P, et al. Acute and post-acute hospitalizations for stroke in France: Recent improvements (20072009). Presse Médicale 2012;41:491-503.

6. Ministère de la santé et des sports, 2010. Ministère du travail, de la solidarité et de la fonction publique, Ministère de l'enseignement supérieur et de la recherche. Plan d'actions national « accidents vasculaires cérébraux http://www.cnsa.fr/documentation/plan actions_avc_-_17avr2010.pdf.

7. Lecoffre $\mathrm{C}$, de Peretti $\mathrm{C}$, Gabet $\mathrm{A}$, et al. National trends in patients hospitalized for stroke and stroke mortality in France, 2008 to 2014. Stroke 2017;48:2939-45.

8. (UNV), 2017. Ministère des Solidarités et de la Santé. Les unités neuro vasculaire (UNV) http://solidarites-sante.gouv.fr/soins-etmaladies/maladies/maladies-cardiovasculaires/accident-vasculairecerebral-avc/article/les-unites-neuro-vasculaire-unv (accessed 28 Mar 2018).

9. Lecoffre $\mathrm{C}$, de Peretti C, Gabet A, et al. L'accident vasculaire cérébral en France : patients hospitalisés pour AVC en 2014 et évolutions 2008-2014. Bull Epidémiol Hebd 2017:84-94.

10. Boudemaghe T, Belhadj I. Data Resource Profile: The French National Uniform Hospital Discharge Data Set Database (PMSI). Int $J$ Epidemiol 2017;46:392-392d.

11. Giroud M, Hommel M, Benzenine E, et al. FRESCO Study. Positive predictive value of french hospitalization discharge codes for stroke and transient ischemic attack. Eur Neurol 2015;74:92-9.

12. Giroud M, Hommel M, Benzenine E, et al. Evaluation of metrologic quality of the french national hospital discharge database for stroke. Bull Epidémiol Hebd 2016;1:8-15.

13. Agence Technique de l'Information sur l'Hospitalisation.. Mise à jour 2014 de la liste de correspondance codes postaux codes géographiques. http://www.atih.sante.fr/mise-jour-2014-de-la-listede-correspondance-codes-postaux-codes-geographiques (accessed 28 Mar 2018).

14. Quan H, Li B, Couris CM, et al. Updating and validating the Charlson comorbidity index and score for risk adjustment in hospital discharge abstracts using data from 6 countries. Am J Epidemiol 2011;173:676-82.

15. Quan $\mathrm{H}$, Sundararajan $\mathrm{V}$, Halfon $\mathrm{P}$, et al. Coding algorithms for defining comorbidities in ICD-9-CM and ICD-10 administrative data. Med Care 2005;43:1130-9.

16. Bannay $\mathrm{A}$, Chaignot $\mathrm{C}$, Blotière $\mathrm{PO}$, et al. The best use of the charlson comorbidity index with electronic health care database to predict mortality. Med Care 2016;54:188-94.

17. Royston P, Ambler G, Sauerbrei W. The use of fractional polynomials to model continuous risk variables in epidemiology. Int J Epidemiol 1999;28:964-74.

18. Krogias C, Bartig D, Kitzrow M, et al. Trends of hospitalized acute stroke care in Germany from clinical trials to bedside. Comparison of nation-wide administrative data 2008-2012. J Neurol Sci 2014;345:202-8.

19. Appelros $\mathrm{P}$, Jonsson $\mathrm{F}$, Åsberg $\mathrm{S}$, et al. Trends in stroke treatment and outcome between 1995 and 2010: observations from RiksStroke, the Swedish stroke register. Cerebrovasc Dis 2014;37:22-9.

20. Koifman J, Hall R, Li S, et al. The association between rural residence and stroke care and outcomes. J Neurol Sci 2016;363:16-20.

21. Emberson J, Lees KR, Lyden P, et al. Effect of treatment delay, age, and stroke severity on the effects of intravenous thrombolysis with alteplase for acute ischaemic stroke: a metaanalysis of individual patient data from randomised trials. Lancet 2014;384:1929-35.

22. Goyal M, Menon BK, van Zwam WH, et al. Endovascular thrombectomy after large-vessel ischaemic stroke: a meta-analysis of individual patient data from five randomised trials. Lancet 2016;387:1723-31

23. Candelise L, Gattinoni M, Bersano A, et al. Stroke-unit care for acute stroke patients: an observational follow-up study. Lancet 2007;369:299-305.

24. Sandercock P, Wardlaw JM, Lindley RI, et al. The benefits and harms of intravenous thrombolysis with recombinant tissue plasminogen activator within $6 \mathrm{~h}$ of acute ischaemic stroke (the third international stroke trial [IST-3]): a randomised controlled trial. Lancet 2012:379:2352-63.

25. Appelros $\mathrm{P}$, Stegmayr $\mathrm{B}$, Terént $\mathrm{A}$. A review on sex differences in stroke treatment and outcome. Acta Neurol Scand 2010;121:359-69.

26. Reid JM, Dai D, Gubitz GJ, et al. Gender differences in stroke examined in a 10-year cohort of patients admitted to a Canadian teaching hospital. Stroke 2008;39:1090-5.

27. Silva GS, Lima FO, Camargo EC, et al. Gender differences in outcomes after ischemic stroke: role of ischemic lesion volume and intracranial large-artery occlusion. Cerebrovasc Dis 2010;30:470-5.

28. Lorenzano S, Ahmed N, Falcou A, et al. Does Sex Influence the Response to Intravenous Thrombolysis in Ischemic Stroke? Stroke 2013;44:3401-6.

29. Sheedy R, Bernhardt J, Levi CR, et al. Are patients with intracerebral haemorrhage disadvantaged in hospitals? Int J Stroke 2014;9:437-42. 
30. Béjot $Y$, Aouba A, de Peretti C, et al. Time trends in hospital-referred stroke and transient ischemic attack: results of a 7-year nationwide survey in France. Cerebrovasc Dis 2010;30:346-54.

31. Peretti Cde, Chin F, Tuppin P, et al. Personnes hospitalisées pour accident vasculaire cérébral en France : tendances 2002-2008. Bull Epidémiol Hebd. http://opac.invs.sante.fr/doc_num.php?explnum id=8003 (accessed 28 Mar 2018)

32. Krishnamurthi RV, Feigin VL, Forouzanfar MH, et al. Global and regional burden of first-ever ischaemic and haemorrhagic stroke during 1990-2010: findings from the Global Burden of Disease Study 2010. Lancet Glob Health 2013;1:e259-e281.

33. Béjot $Y$, Daubail $B$, Jacquin $A$, et al. Trends in the incidence of ischaemic stroke in young adults between 1985 and 2011: the dijon stroke registry. J Neurol Neurosurg Psychiatry 2014;85:509-13.
34. Brazzelli M, Chappell FM, Miranda H, et al. Diffusion-weighted imaging and diagnosis of transient ischemic attack: DWI and Diagnosis of TIA. Ann Neurol 2014;75:67-76.

35. Ovbiagele B, Kidwell CS, Saver JL. Epidemiological impact in the United States of a tissue-based definition of transient ischemic attack. Stroke 2003;34:919-24.

36. Aboa-Eboulé C, Mengue D, Benzenine E, et al. How accurate is the reporting of stroke in hospital discharge data? A pilot validation study using a population-based stroke registry as control. $J$ Neurol 2013;260:605-13.

37. Haesebaert J, Termoz A, Polazzi S, et al. Can hospital discharge databases be used to follow ischemic stroke incidence? Stroke 2013;44:1770-4. 